\title{
Deep structure of the Nagamachi-Rifu fault deduced from small aperture seismic array observations
}

\author{
Kazutoshi Imanishi, Hisao Ito, Yasuto Kuwahara, Yutaka Mamada, Takanobu Yokokura, Naomi Kano, \\ Kazuo Yamaguchi, and Akiko Tanaka \\ GSJ/National Institute of Advanced Industrial Science and Technology, AIST Tsukuba Central 7, \\ 1-1, Higashi 1-Chome, Tsukuba-shi, Ibaraki-ken 305-8567, Japan
}

(Received December 28, 2001; Revised June 4, 2002; Accepted June 4, 2002)

\begin{abstract}
A seismic reflection survey using both explosives and vibrators was conducted in June 2001 around the Nagamachi-Rifu fault, northeastern Japan. We carried out observations of four small aperture seismic arrays in the area to reveal detailed structures of the fault. Array analysis was applied to waveform data from 15 explosives to obtain P-wave scatterer distributions in the area. The obtained P-wave scatterer distribution correlates in space with microearthquake activities and heterogeneous structures such as S-wave reflectors, a structure of caldera, and Mohorovicic discontinuity. We could also image that a sub-horizontal layer with a length of about $10 \mathrm{~km}$ exists in the deep extension of the Nagamachi-Rifu fault beneath the seismogenic layer.
\end{abstract}

\section{Introduction}

It is hypothesized that there exist deep extensions of active faults beneath seismogenic zones and aseismic slip on the extensions control the generation of inland large earthquakes (Iio, 1996). This leads to that it is important to explore deep structures and geometries of active faults. In general, the geometry of faults can be inferred from hypocenters of aftershocks. However, seismic activities at most of active faults in Japan are very low, so that we cannot reveal the geometry until an occurrence of a large earthquake. One possible approach to image fault geometries is a reflection survey by using artificial sources such as explosive or vibrator. It has been understood that imaging deep crustal structures under the Japanese islands is difficult due to strong attenuation of seismic waves. Recently, Sato and Hirata (1998) and Yokokura et al. (2000) indicated possibilities to estimate deep structures of active faults in Japan if a reflection survey is conducted with sufficient specifications.

There are a lot of reports that seismic bright spots beneath seismogenic zones were observed as reflection phases (e.g., Makovsky and Klemperer, 1999; Matsumoto and Hasegawa, 1996; Sanford et al., 1973). Since these reflection phases have anomalously high amplitudes, the bright spots are believed to be a layer filled with fluids such as melt bodies or water. The existence of fluids beneath seismogenic zones may affect the long-term structural and compositional evolution of fault zones, and change the fault strength (e.g., Hickman et al., 1995). These influences may enhance stress concentration in the seismogenic zone leading to mechanical failure. Therefore we also need to investigate inhomogeneous structures under seismogenic zones in order to better

Copy right(C) The Society of Geomagnetism and Earth, Planetary and Space Sciences (SGEPSS); The Seismological Society of Japan; The Volcanological Society of Japan; The Geodetic Society of Japan; The Japanese Society for Planetary Sciences. understand how an earthquake occurs.

Nagamachi-Rifu fault, the B class active reverse fault, is running through the center of Sendai City, Japan (Fig. 1). The length of the fault is estimated about $20 \mathrm{~km}$ (Research Group for Active Faults of Japan, 1991). Although the surface trace of the fault can be seen, the geometry of the fault at depths is not known. An earthquake with a magnitude of 5.0 occurred at a depth of $12 \mathrm{~km}$ on 15 September 1998 . Epicenter of the event was located about $10 \mathrm{~km}$ to the northwest of the Nagamachi-Rifu fault. Focal mechanism of the main shock and aftershock distribution indicate that the event is a reverse fault-type and its fault plane dips to the northwest at an angle of about $30^{\circ}$ (Umino et al., 2002). They suggest that this event was a slip at a deepest portion of the Nagamachi-Rifu fault, assuming that the fault dip decreases with increasing depth. However, it is still unclear how the deep extension of the fault exists. From the foreshocks and aftershocks of the M5.0 event, Hori et al. (1999) found distinct later phases, followed the direct $\mathrm{S}$-wave by $2.5 \mathrm{~s}$, at nearby stations around the epicenter of the M5.0 event. Using travel times of these later phases, they mapped the depth distribution of distinct reflector. It locates beneath the fault plane of the M5.0 event at depths ranging 15-21 km dipping north-northeast with an angle of about $27^{\circ}$. From spectral amplitude ratios of reflected S-wave to direct S-wave, Umino et al. (2002) reported that $\mathrm{S}$-wave velocity in the reflector is about $1.0 \mathrm{~km} / \mathrm{s}$ and its thickness is about $100 \mathrm{~m}$. This observation suggests that there exist a thin reflector body partially filled with fluids beneath the Nagamachi-Rifu fault.

Seismic array analysis is one of the most effective techniques to estimate inhomogeneous structures of the earth (e.g., Christopher and Lay, 1989; Revenaugh, 1995; Spudich and Bostwick, 1987). In particular, ray direction approaching to array would be determined in detail by analyzing seismograms recorded by small aperture array with station sepa- 


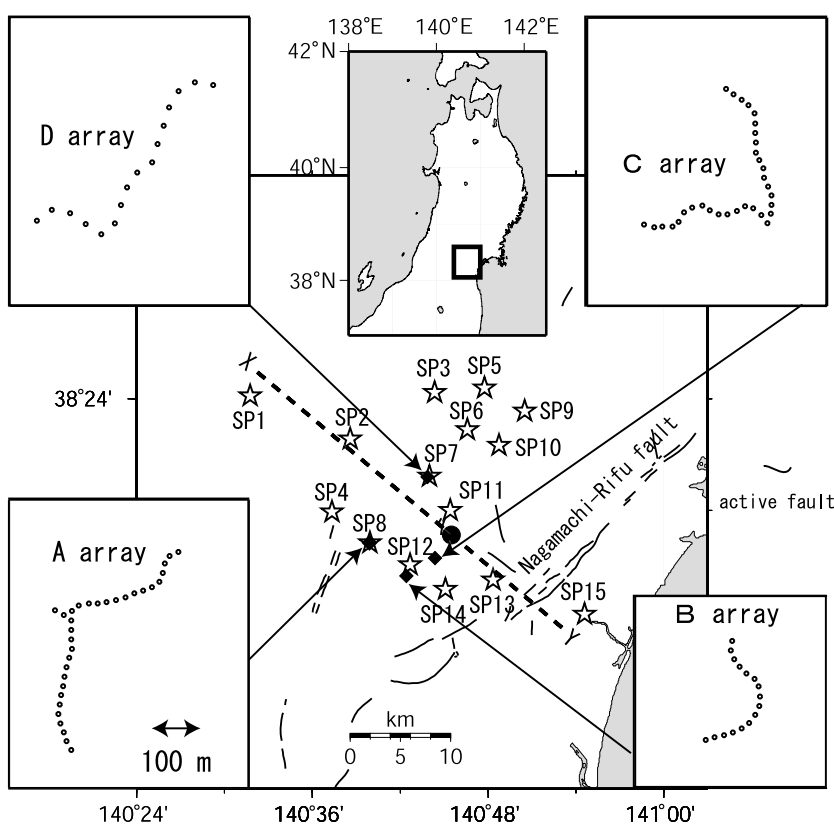

Fig. 1. Map showing locations of seismic arrays and shot points. Stars represent shot points of explosives from SP1 to SP15. The solid circle denotes the epicenter of an earthquake (M5.0) occurred on 15 September 1998. Array profiles are shown in four panels. Open circles show observation sites.

rations of several tens of meters (e.g., Kuwahara et al., 1997; Matsumoto et al., 1998; Wagner, 1998). The location and tangential plane of a reflector can be estimated by the slowness vector evaluated by the array analysis and the travel time of a reflection phase (e.g., Takenaka, 2000).

In June 2001, a seismic reflection survey using both explosives and vibrators was conducted to reveal the deep structure of the Nagamachi-Rifu fault. The details of the observations are described by Hasegawa et al. (2001). In this study, array analysis is applied to waveform data from explosives for imaging spatial distribution of seismic scatterers in the crust and inferring the geometry of deep extension of the Nagamachi-Rifu fault.

\section{Observations}

We deployed 4 small aperture seismic arrays around the Nagamachi-Rifu fault during the reflection survey. A, B, and C-arrays shown in Fig. 1 were composed of $2 \mathrm{~Hz}$ threecomponents seismometers (Mark Products, L22E) with a spacing of $20 \mathrm{~m}$, while D-array was constituted of 10 $\mathrm{Hz}$ three-components seismometers (OYO-Geospace, GS20DM) with a spacing of $40 \mathrm{~m}$. These seismometers were installed two-dimensionally to detect scattered and reflected waves, which may come from various directions. The sampling frequency of recorders was $500 \mathrm{~Hz}$. Waveform data from 15 explosives were recorded by manual triggering. The locations of these explosives are shown by stars in Fig. 1. Dynamites of 70-130 kg were exploded in borehole at these locations. An example of vertical record section for shot SP3 at A-array is shown in Fig. 2. The waveform data are processed with a band-pass filter of 5 to $15 \mathrm{~Hz}$. Several coherent phases are recognized after direct $\mathrm{P}$ onset.

\section{Analysis}

\subsection{Velocity structure}

$\mathrm{P}$-wave travel time curve is determined by using $\mathrm{P}$-wave arrival times recorded at the arrays and those recorded at Hinet (Okada et al., 2000) from 15 explosives, whose epicentral distances are less than $80 \mathrm{~km}$ (crosses in Fig. 3). Based on the reciprocal method, we determined a three layered P-wave velocity structure of the studied area; $3.4 \mathrm{~km} / \mathrm{s}$ (depth $\leq 1.3$ $\mathrm{km}), 5.3 \mathrm{~km} / \mathrm{s}(1.3 \mathrm{~km} \leq \mathrm{depth} \leq 3.1 \mathrm{~km})$, and $6.0 \mathrm{~km} / \mathrm{s}(3.1$ $\mathrm{km} \leq$ depth). A dashed line in Fig. 3 represents a theoretical travel time based on the velocity structure. This structure is used to calculate the travel times of scattered waves in the following analysis.

\subsection{Method of estimating scatterer distribution}

Estimation of scatterer distribution is performed on the assumption that seismic coda waves are composed of single scattering waves. This simple assumption enables us to infer scattering structures deterministically. We also assume that the effect of mode-converted waves from $\mathrm{P}$ to $\mathrm{S}$ waves is small on vertical component. Thus only $\mathrm{P}$ to $\mathrm{P}$ scatter is considered in analysis of vertical components.

We used 3-D grid points with a spacing of $1 \mathrm{~km}$ in the studied area. To investigate whether a scattered energy is really originated from a particular grid point or not, we conducted semblance analysis (Neidell and Tarner, 1971). The semblance coefficient at a particular point is related to the magnitude of scattering there. A high semblance coefficient implies effective excitation of scattered waves. The semblance analysis has capability to detect coherent waves even if the seismic signals are small. The semblance coefficient for a grid points $\mathbf{X}_{k}$ is

$$
\operatorname{SEM}\left(\mathbf{X}_{k}\right)=\frac{\sum_{t=-W / 2}^{W / 2}\left(\sum_{i=1}^{M} f_{i}\left(T_{\mathrm{PP}}(i)+t\right)\right)^{2}}{M \sum_{t=-W / 2}^{W / 2} \sum_{i=1}^{M} f_{i}^{2}\left(T_{\mathrm{PP}}(i)+t\right)}
$$

where $T_{\mathrm{PP}}(i)$ is the arrival time of P-P scattered waves and given by

$$
T_{\mathrm{PP}}(i)=t_{p}\left(\mathbf{X}_{s}, \mathbf{X}_{k}\right)+t_{p}\left(\mathbf{X}_{k}, \mathbf{X}_{i}\right)
$$

where $\mathbf{X}_{s}, \mathbf{X}_{k}$, and $\mathbf{X}_{i}$ are the coordinates of shot points, grid points, and stations, respectively. $t_{p}\left(\mathbf{X}_{s}, \mathbf{X}_{k}\right)$ and $t_{p}\left(\mathbf{X}_{k}, \mathbf{X}_{i}\right)$ represent the travel times of $\mathrm{P}$-wave from a shot point to a grid point, and those from a grid point to a station. $M$ is the number of stations and $f_{i}(t)$ is the amplitude of waveforms of $i$-th station at the time $t$. $W$ denotes the length of time window. This calculation was performed for all set of shotreceiver array combinations except for noisy data. Averaging the semblance coefficients determined by all shot-receiver array combinations, we get P-wave scatterer distribution. Since the present approach only uses $\mathrm{P}$ to $\mathrm{P}$ scattering, there is a possibility that multiple $\mathrm{P}$ to $\mathrm{P}$ scatterers are mapped at deeper depths. However the average of the semblance coefficients will reduce the effect of multiple scatterers.

To investigate the resolution of this procedure, we performed a simulation test. We assumed six scatterers shown in Fig. 4(a) at the depth of 10 and $20 \mathrm{~km}$ along a line X-Y shown in Fig. 1. In the same case of shot-receiver array combinations as observed data, synthetic seismograms of scattered $\mathrm{P}$-waves were computed. Scattered P-wave is represented 


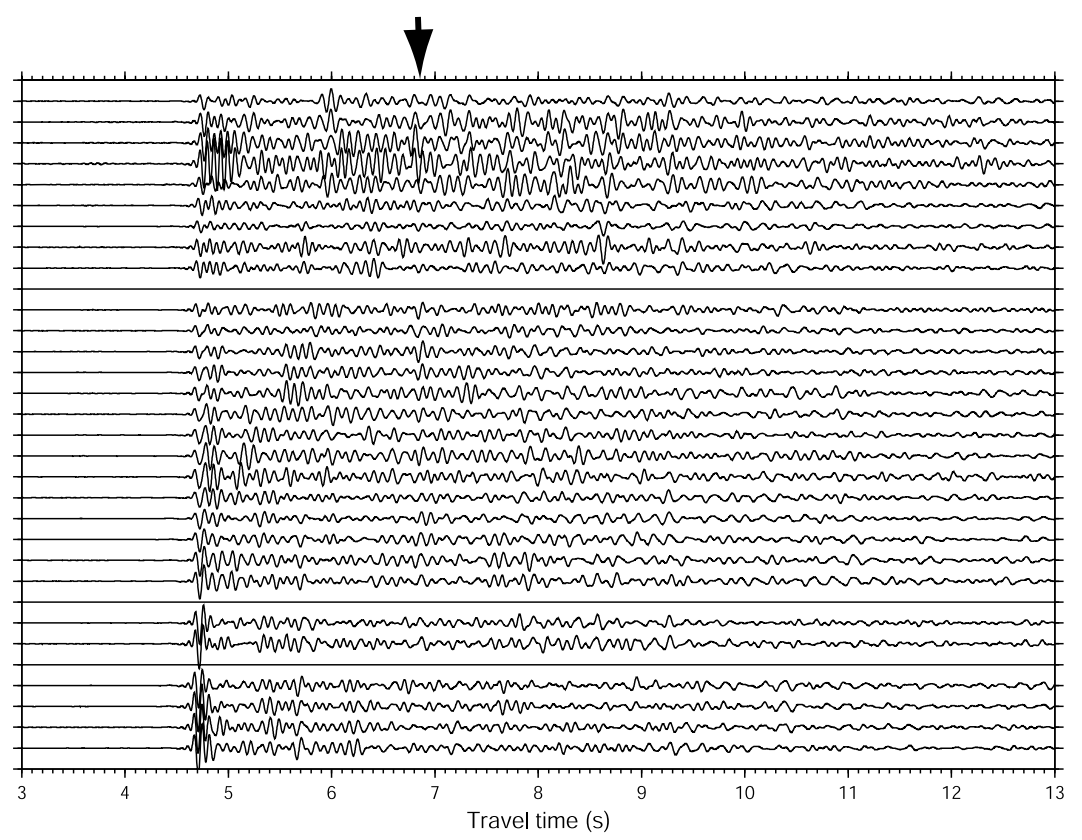

Fig. 2. An example of waveforms recorded by the A array for shot SP3. Band-pass filter of $5-15 \mathrm{~Hz}$ is applied. A later phase indicated by an arrow is estimated to come from deeper portions of the Nagamachi-Rifu fault.

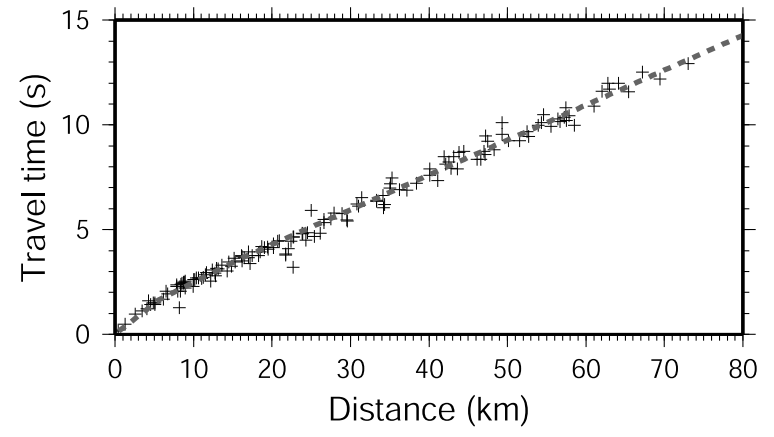

Fig. 3. Travel times of P-wave recorded at arrays and Hi-net from 15 explosives. A dashed line represents theoretical travel time calculated from a P-wave velocity structure obtained in this study.

by a sine wave with a frequency of $12.5 \mathrm{~Hz}$. The synthetic seismograms are evaluated with normally distributed random noise with an average of zero and with a standard deviation of $\pm 10 \%$ of signals. The length of time window of semblance calculation is $0.2 \mathrm{~s}$. After averaging the semblance coefficient distributions calculated from all shot-receiver array combinations, the scatterers can be imaged correctly for the central portion whose resolution is estimated as to be about a few kilometers (Fig. 4(b)). This resolution is sufficient to discuss the inhomogeneous structure in the studied area. In the next section, we consider only the portion of the cross section between $-10 \mathrm{~km}$ and $10 \mathrm{~km}$ since the resolution near the edges is not good. The distribution of relatively high semblance coefficients shows a circular arc. This is due to a lack of resolution on an elliptical plane whose focus are a shot and an array, since the arrival times are similar on the elliptical plane. Therefore, we need to pay attention to the circular arc when we interpret the spatial distribution of scatterers.
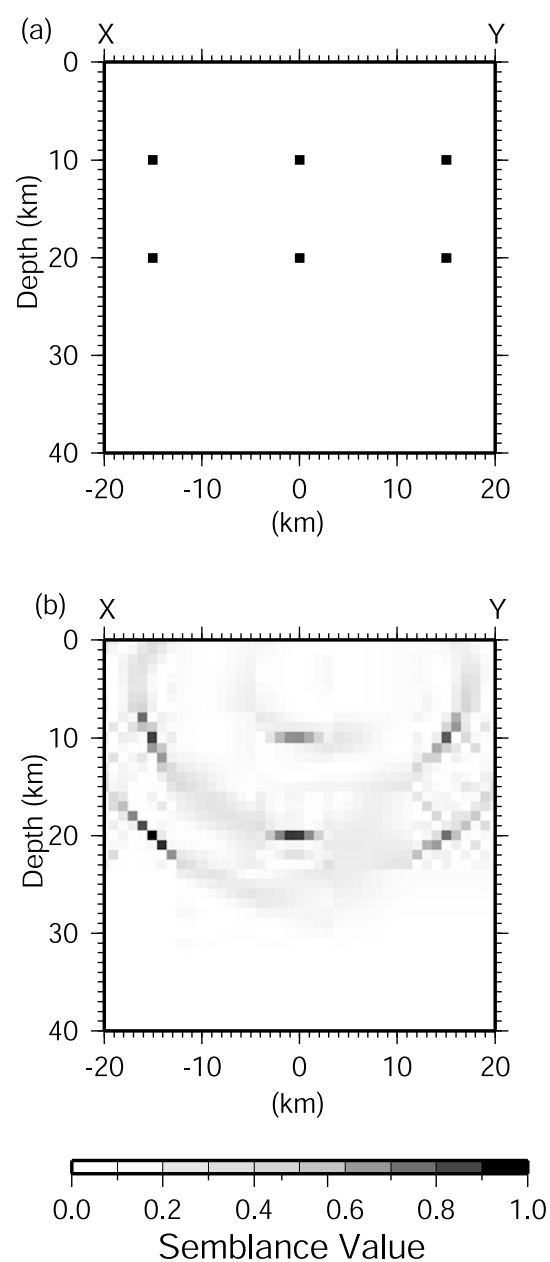

Fig. 4. Resolution checks. (a) Six scatterers (solid squares) are set to be at the depth of 10 and $20 \mathrm{~km}$ along a line X-Y shown in Fig. 1. (b) Vertical cross section of estimated semblance coefficients along a line $\mathrm{X}-\mathrm{Y}$ shown in Fig. 1. The gray scale at the bottom shows averaged values of semblance coefficients. 


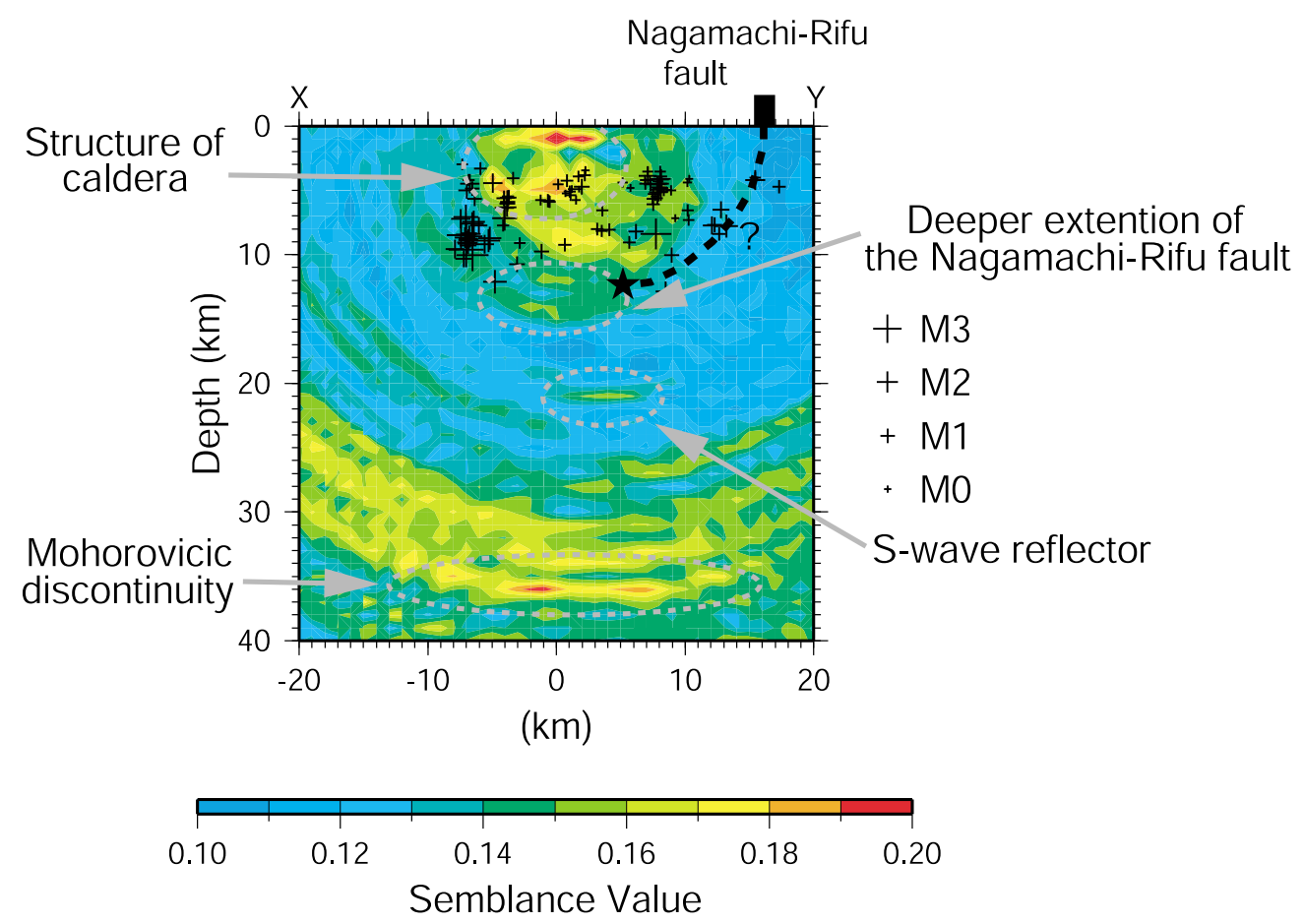

Fig. 5. Vertical cross sections of P-wave scatterer distribution along a line X-Y shown in Fig. 1. Color bar shows averaged values of semblance coefficients. A star represents the location of the M5.0 earthquake. Hypocenters determined by Yoshimoto et al. (2000) are shown by crosses which are scaled to the local magnitude.
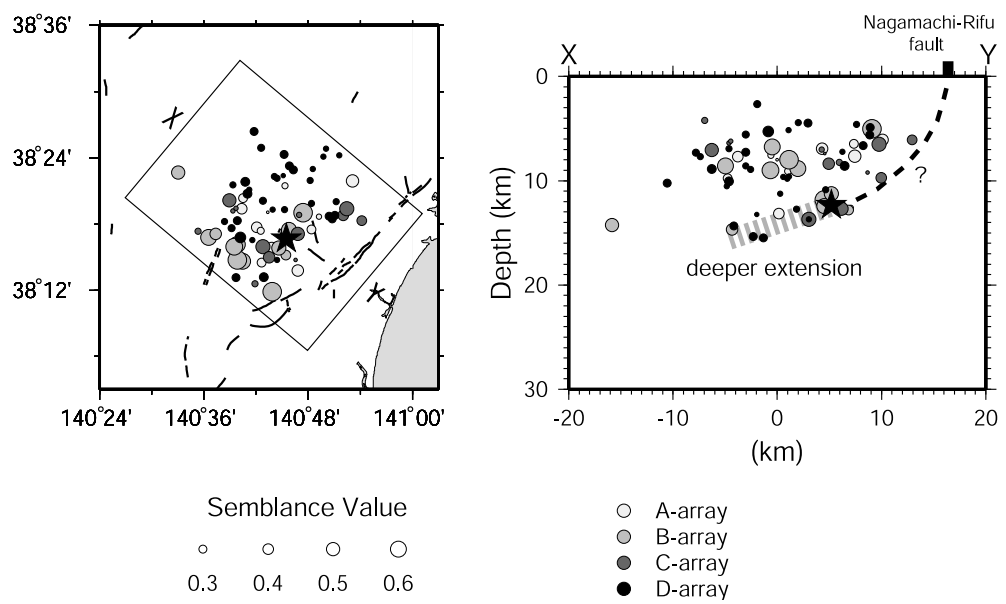

Fig. 6. Deep extension of the Nagamachi-Rifu fault (a gray bold broken line). Circles denote reflection/scatterer points and those sizes represent semblance values. Stars are the location of the M5.0 earthquake.

\subsection{P-wave scatterer distribution in and around the Nagamachi-Rifu fault}

The waveforms were processed with a band-pass filter of 10 to $15 \mathrm{~Hz}$. We adopted $0.2 \mathrm{~s}$ for the length of time window of semblance calculation. The $0.2 \mathrm{~s}$ interval can include at least two wavelengths of analyzed seismograms. In order to exclude the effect of direct P-waves, muting of the direct $\mathrm{P}$-waves was applied. Figure 5 shows a vertical cross section across the fault of the M5.0 event whose hypocenter is shown by a star. The peak values of the semblance are smaller than those of the synthetic test. The main reasons are that the velocity structure determined in this study is not always accurate, the waveform shapes among the stations are not com- pletely same because of the effect of surface geology, and the observed seismograms have more contributions from scattered waves than the synthetic seismograms. In this study, we only consider the regions where the semblance values are relatively high and other expected geophysical evidences exist. We find a region with relatively high semblance coefficients at a depth of about $12 \mathrm{~km}$. Nakamura et al. (2002) also found about 7-km-long sub-horizontal reflector at the same location using data recorded at two $10-\mathrm{km}$-long off-line arrays. This high semblance region may correspond to scatterers situated at a deep extension of the Nagamachi-Rifu fault. We will investigate this possibility in detail in the next section. High semblance coefficients region are also distributed 
at a depth of about $20 \mathrm{~km}$. It seems that the area coincide with S-wave reflector estimated by Hori et al. (1999). We also find a region with high semblance coefficients at depths of less than $10 \mathrm{~km}$. Yoshida (2001) suggested that there exist calderas in this region and unexposed plutons exist at middle crustal depth beneath the calderas. These scatterers are probably related to structures of the calderas. Another area having high semblance coefficients is found at a depth of about $35 \mathrm{~km}$. The depth corresponds to Mohorovicic discontinuity that had been reported by Zhao et al. (1990) from seismic tomography investigation. Based on the analysis of receiver functions, Yoshimoto et al. (2001) also identified distinct P$\mathrm{S}$ converted phases which are relevant with $\mathrm{S}$-wave reflector, caldera structure, and Mohorovicic discontinuity.

\subsection{Deep extension of the Nagamachi-Rifu fault}

When a reflection plane exists, the reflection point varies depending on locations of the source and station. Thus stacking of scatterer distributions determined by all shot-receiver array combinations does not always emphasize the image of reflection plane. Therefore, we adopt another approach to image deep extension of the Nagamachi-Rifu fault.

Since we do not have any precise information on the geometry of the deep extension, we assumed a single flat reflector which passes through the hypocenter of the M5.0 event with a same strike as that of the Nagamachi-Rifu fault and a dip angle of $30^{\circ}$. Then theoretical reflection points for each shot-receiver array combinations are obtained based on a homogeneous velocity structure, and the theoretical travel times of reflection phase $\left(T_{R}\right)$ are also calculated by using the velocity structure obtained in this study. Reflection phases from deep extension can arrive at the time around $T_{R}$ if the deep extension really exists.

For each shot-receiver array waveforms, we made plots of time series of the arrival azimuth, the slowness and the semblance value showing the maximum semblance in each time window at every time intervals of $0.1 \mathrm{~s}$. The frequency range of waveforms and the time window for the semblance computation were same as those of the above section. In order to extract information on the deep extension, we only consider the arrival time from explosives in $1 \mathrm{~s}$ before and after the theoretical travel time $\left(T_{R}\right)$. Here the $2 \mathrm{~s}$ interval was adopted by considering the difference of travel times between theoretical and observed reflection/scatterer phases. The permissible range of $\pm 1 \mathrm{~s}$ means that we search the region with a thickness of $6 \mathrm{~km}$ including the assumed extension of the fault. Furthermore we picked up only the arrival azimuth and slowness whose semblance coefficient is greater than the average one in $10 \mathrm{~s}$ interval just after $1 \mathrm{~s}$ later the P-wave arrival time of the time series. Most of P-P scatterers in the studied area are included in this $10 \mathrm{~s}$ interval. By using ray tracing and considering arrival time from the explosives, each arrival azimuth and slowness were converted to their locations of reflection/scatterer points assuming a P-P scatterer (Fig. 6). Most of reflection/scatterer points are distributed at depths less than $10 \mathrm{~km}$. These points should be considered to be scatterers in the caldera structure. However, it should be also noted that the reflection/scatterer points are clearly concentrated in the deep extension of the fault. As seen in Fig. 6, the length of the layer is estimated to be at least 10 $\mathrm{km}$. The example of phases coming from the sub-horizontal layer is shown by an arrow in Fig. 2.

\section{Discussion}

P-wave scatterer distribution (Fig. 5) shows that the northwest side of the Nagamachi-Rifu fault is strongly heterogeneous for shallower depth than $10 \mathrm{~km}$. Seismic reflection profile (Hasegawa et al., 2001) supports this result. Carrying out a temporal seismic observation composed of 16 high-sensitivity stations, Yoshimoto et al. (2000) investigated microearthquake activity around the Nagamachi-Rifu fault. Hypocentral distributions are shown by crosses in Fig. 5. The focal depths of these events are located in the range between 3 and $13 \mathrm{~km}$. Regardless of their high sensitivity observation, most of hypocenters are concentrated in the northwest side of the fault. This suggests that heterogeneous structures are related to microearthquake activities.

It has been reported that sub-horizontal detachment exists in the deep extension of active faults (e.g., Ikeda, 1992; Ito, 1994). Inferred from the crustal strain data, Iio (1996) and Komatsubara and Awata (2001) revealed that aseismic slip on the detachment fault is a possible generating process of the 1995 southern Hyogo prefecture earthquake (M7.2) and 1970 southeastern Akita prefecture earthquake (M6.2), respectively. In the present study, we detected a sub-horizontal layer such as detachment fault at the base of the seismogenic zone. There is a possibility that aseismic slip was concentrated in this sub-horizontal layer and the occurrence of the M5.0 event is related with the nucleation process of a future large earthquake.

A continuous GPS observation is one of the most direct methods to estimate an aseismic slip on the deep extension of the fault. In order to observe a localized deformation around the Nagamachi-Rifu fault, a dense GPS array around it was constructed (Sagiya et al., 2001). Analyzing these data, Nishimura et al. (2001) found that the localized zone with high compressive strain-rate area can be located on the assumed deep extension of the fault. As a cause of the localized compression, they suggested quasi-static sliding on the deep extension of the fault. In order to reveal deformation processes at depths which will lead to a future large earthquake, we need to monitor slow slip on the deep extension of the fault with the dense GPS array observations.

\section{Conclusion}

We carried out small aperture seismic array observations around the Nagamachi-Rifu fault to image detail crustal structure. Array analysis was applied to waveform data from 15 explosives. We assumed 3-D grid points with a spacing of $1 \mathrm{~km}$ in a studied area. After band-pass filtering in a frequency range from 10 to $15 \mathrm{~Hz}$, semblance coefficients were calculated at each grid points. We interpreted that a high semblance coefficient represents effective excitation of scattered waves. The obtained P-wave scatterer distribution correlates in space with microearthquake activities and heterogeneous structures such as S-wave reflectors, a structure of caldera, and Mohorovicic discontinuity. In order to image the geometry of the deep extension of the fault, we used ray tracing to convert slowness vectors to their reflection or scatterer points. Estimated image shows that a sub-horizontal layer with a length of about $10 \mathrm{~km}$ exists in the deep exten- 
sion of the Nagamachi-Rifu fault at the base of the seismogenic zone in a depth of $12-15 \mathrm{~km}$.

Acknowledgments. We express our gratitude to Mr. R. Sanda, Mr T. Nishino, and Mr. T. Shibuya who kindly supported the observation reported here. We thank Dr. K. Yoshimoto who gave us hypocentral locations for microearthquake around the NagamachiRifu fault. Comments by Dr. N. Umino and one anonymous reviewer were helpful in improving the manuscript. We used Hinet data to determine the velocity structure. Ms. M. Pervoukhina read the P-wave onset of the Hi-net data. Some of the figures have been generated using the Generic Mapping Tool (Wessel and Smith, 1991). This study was conducted as a part of the "Comprehensive Research on Slip and Flow Processes in and below the Seismogenic Region" supported by the Special Coordination Fund of the Ministry of Education, Culture, Sports, Science and Technology (MEXT)

\section{References}

Christopher, S. L. and T. Lay, Inversion of P coda for isotoropic scatters at the Yucca Flat test site, Bull. Seism. Soc. Am., 79, 790-804, 1989.

Hasegawa, A., H. Ito, T. Iwasaki, and T. Ikawa, Deep structure of Nagamachi-Rifu fault as inferred from seismic expeditions, the Proceedings of the International Symposium on Slip and Flow Processes in and Below the Seismogenic Region, 67-72, 2001.

Hickman, S., R. Sibson, and R. Bruhn, Introduction to special section: Mechanical involvement of fluids in faulting, J. Geophys. Res., 100, 12831-12840, 1995

Hori, S., N. Umino, Y. Asano, and A. Hasegawa, S-wave reflectors in the crust of northeastern Japan, Prog. Abstr. Seism. Soc. Japan 1999 Fall meeting, P140, 1999 (in Japanese).

Iio, Y., A possible generating process of the 1995 Southern Hyogo Prefecture earthquake, J. Seism. Soc. Japan, 49, 103-112, 1996 (in Japanese with English abstract)

Ikeda, Y., Japanese thrust faults: A possibility of flake tectonics, Monthly Chikyu, Extra 5, 1992 (in Japanese)

Ito, T., Will the median tectonic line move?; A new discovery of crustal structure, Zisin Journal, 17, 27-32, 1994 (in Japanese).

Komatsubara, T. and Y. Awata, Analyses of pre-, co-, and post-seismic vertical crustal movement on the southeastern Akita Earthquake of 1970-An evidence of pre-slip at the base of the seismogenic layer, J. Seism. Soc Japan, 54, 33-44, 2001 (in Japanese with English abstract).

Kuwahara, Y., H. Ito, H. Kawakatsu, T. Ohminato, and T. Kiguchi, Crustal heterogeneity as inferred from seismic coda wave decomposition by small-aperture array observation, Phys. Earth Planet. Inter., 104, 247 256,1997

Makovsky, Y. and S. L. Klemperer, Measuring the seismic properties of Tibetan bright spots: Evidence for free aqueous fluids in the Tibetan middle crust, J. Geophys. Res., 104, 10795-10825, 1999.

Matsumoto, S. and A. Hasegawa, Distinct S wave reflector in the midcrust beneath Nikko-Shirane volcano in the northeastern Japan arc, J. Geophys. Res., 101, 3067-3083, 1996.

Matsumoto, S., K. Obara, and A. Hasegawa, Imaging P-wave scatter distribution in the focal area of the 1995 M7.2 Hyogo-ken Nanbu (Kobe) Earthquake, Geophys. Res. Lett., 25, 1439-1442, 1998.

Nakamura, A., Y. Asano, and A. Hasegawa, Estimation of deep fault geometry of the Nagamachi-Rifu fault from seismic array observations, Earth
Planets Space, 54, this issue, 1027-1031, 2002.

Neidell, N. S. and M. T. Tarner, Semblance and other coherency measures for multichannel data, Geophysics, 36, 482-497, 1971.

Nishimura, T., T. Sagiya, T. Tada, and S. Miura, High strain rate west of the Nagamachi-Rifu fault, northern Japan, observed by a dense GPS array, the Proceedings of the International Symposium on Slip and Flow Processes in and Below the Seismogenic Region, 357-362, 2001.

Okada, Y., K. Kasahara, S. Hori, K. Obara, and S. Aoi, Hi-net (1): Outline, Prog. Abstr. Seism. Soc. Japan 2000 Fall meeting, P004, 2000.

Research Group for Active Faults of Japan, Active Faults of Japan, University of Tokyo Press, Tokyo, 1991 (in Japanese).

Revenaugh, J., Relation of the 1992 Landers, California, earthquake sequence to seismic scattering, Science, 270, 1344-1347, 1995.

Sagiya, T., T. Nishimura, S. Miura, Y. Iio, and T. Tada, Investigation of slip at deep extension of fault using dense GPS array observations, Monthly Chikyu, 23, 321-327, 2001.

Sanford, A. R., O. Alptekin, and T. R. Toppozada, Use of reflection phases on microearthquake seismograms to map an unusual discontinuity beneath the Rio Grande Rift, Bull. Seism. Soc. Am., 63, 2021-2034, 1973.

Sato, H. and N. Hirata, Deep structure of active faults and evolution of the Japanese islands, Kagaku, 68, 63-71, 1998 (in Japanese).

Spudich, P. and T. Bostwick, Studies of the seismic coda using an earthquake cluster as a deeply buried seismograph array, J. Geophys. Res., 92 10526-10546, 1987.

Takenaka, H., A scheme for estimating the location and tangential plane of a reflector, Earth Planets Space, 52, 299-303, 2000.

Umino, N., T. Okada, and A. Hasegawa, Foreshock and aftershock sequence of 1998 M5.0 Sendai, northeastern Japan, earthquake and its implications for earthquake nucleation, Bull. Seism. Soc. Am., 2002 (in press).

Umino, N., H. Ujikawa, S. Hori, and A. Hasegawa, Distinct S-wave reflectors (bright spots) detected beneath the Nagamachi-Rifu fault, NE Japan, Earth Planets Space, 54, this issue, 1021-1026, 2002.

Wagner, G. S., Local wave propagation near the San Jacinto fault zone, southern California: Observations from a three-component seismic array, J. Geophys. Res., 103, 7231-7246, 1998

Wessel, P. and W. H. F. Smith, Free software helps map and display data, EOS Trans. $A G U, \mathbf{7 2}, 441,445-446,1991$.

Yokokura, T., T. Miyazaki, T. Urabe, N. Kano, K. Yamaguchi, T. Kiguchi, A. Tanaka, T. Yokota, M. Komazawa, Y. Kuwahara, Y. Ogawa, Y. Mitsuhata, I. Hasegawa, H. Kato, Y. Watanabe, K. Nakamura, and H Ito, Deep seismic profiling in Japan, Study on deep crust, 9-27, 2000 (in Japanese with English abstract).

Yoshida, T., The evolusion of arc magmatism in the NE Honshu arc, Japan, Tohoku Geophys. J., 36, 131-149, 2001.

Yoshimoto, K., N. Uchida, H. Sato, M. Ohtake, N. Hirata, and K. Obara, Microseismicity around the Nagamachi-Rifu fault, Miyagi prefecture, Northern Japan, J. Seism. Soc. Japan, 52, 407-416, 2000 (in Japanese with English abstract).

Yoshimoto, K., T. Okada, and A. Hasegawa, Local crustal structure around the Nagamachi-Rifu fault derived from receiver functions, the Proceedings of the International Symposium on Slip and Flow Processes in and Below the Seismogenic Region, 73-76, 2001.

Zhao, D., S. Horiuchi, and A. Hasegawa, 3-D seismic velocity structure of the crust and the uppermost mantle in the northeastern Japan arc, Tectonophys., 181, 135-149, 1990.

K. Imanishi (e-mail: imani@ni.aist.go.jp), H. Ito, Y. Kuwahara, Y. Mamada, T. Yokokura, N. Kano, K. Yamaguchi, and A. Tanaka 